\title{
Initial single centre experience with Barrel VRD stent in large neck aneurisms
}

\section{Cristian Mihalea ${ }^{1,2}$, Felicia Otilia Humulescu ${ }^{3,4}$, Hazem Abdelkhalek $^{1,5}$, Sorin Pescariu ${ }^{6}$, Bogdan Valeriu Popa $^{7}$, Horia Ples $^{1}$}

\author{
1 Department of Neurosurgery, "Victor Babes" University of Medicine \\ and Pharmacy, Timisoara, RomANIA \\ 2 Department of Interventional Neuroradiology, NEURI Brain \\ Vascular Center, Bicêtre Hospital, Le Kremlin-Bicêtre, FRANCE \\ ${ }^{3}$ Bucharest University of Economic Studies, Faculty of Cybernetics, \\ Statistics and Economic Informatics, ROMANIA \\ ${ }^{4}$ Bucharest University of Medicine and Pharmacy Faculty, Faculty of \\ Dental Medicine, ROMANIA \\ ${ }^{5}$ Department of Neuropsychiatry, Tanta University Hospital, Tanta, \\ EGYPT \\ ${ }^{6}$ Cardiology Department, "Victor-Babes" University of Medicine and \\ Pharmacy, Timisoara, RomanIA \\ 7 Department of Radiology and Medical Imaging, "Floreasca" Clinical \\ Emergency Hospital, "Carol Davila" University of Medicine and \\ Pharmacy, Bucharest, ROMANIA
}

\begin{abstract}
Introduction. Despite the use of new techniques, such as Y-stenting, the waffle-cone technique and intrasaccular flow disrupters the treatment of wide-neck bifurcation aneurysms is still challenging, especially for those where adjacent branches are arising at the neck level. Moreover, the use of flow diverter stents in bifurcation aneurysms has been proposed by several teams, although the results remain controversial.

This study is reflecting initial experience in our department with a relatively new device available on the market: Barrel VRD stent. The unique design feature of the device is the "belly-like" central part of the stent which protects the adjacent branches.

Methods. We retrospectively reviewed all patients in whom stenting with braided or laser-cut stents had been performed in our center. Three patients were identified and analyzed. Technical success, complications, immediate angiographic outcomes, procedural data, are reported here.

Results. One MCA bifurcation and two basilar tip large neck aneurysms with one branch arising from the neck level have been identified. Technical success was achieved in all procedures. Overall procedure-related morbidity and mortality was $0 \%$. In the immediate post-treatment angiography, adequate occlusion (neck remnant or total occlusion) was observed in all patients. Short- and mild-term followup angiography showed adequate occlusion of the aneurysms.
\end{abstract}

Conclusions. In this small case series, retrospective single-center analysis we showed

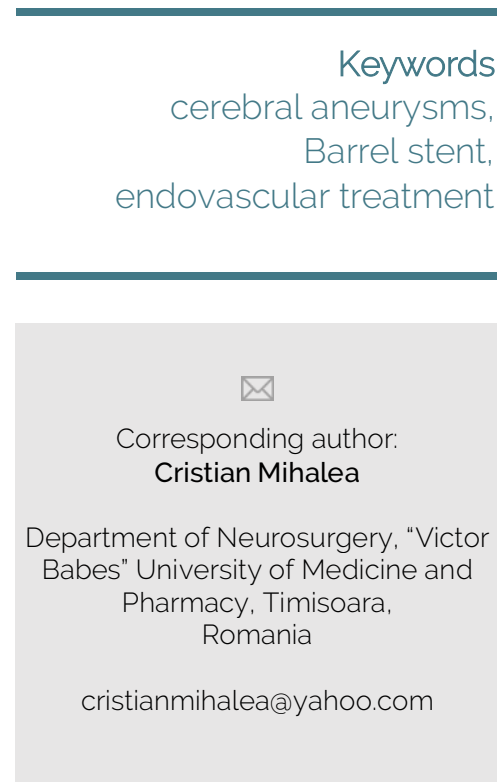

Copyright and usage. This is an Open Access article, distributed under the terms of the Creative Commons Attribution Non-Commercial No Derivatives License (https://creativecommons .org/licenses/by-nc-nd/4.0/) which permits noncommercial re-use, distribution, and reproduction ded the original work is unaltered and is properly cited.

The written permission of the Romanian Society of Neurosurgery must be obtained for commercial re-use or in order to create a derivative work

ISSN online 2344-4959

(c) Romanian Society of Neurosurgery

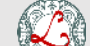

First published

June 2019 by

London Academic Publishing wwww.lapub.co.uk 
that Barrel VRD - stent assisted coiling is a safe and feasible technique. Moreover, it offers an elegant and effective endovascular solution for large neck basilar tip aneurysms on which the neurosurgical clipping remains challenging.

\section{INTRODUCTION}

Endovascular treatment is the standard first-line therapy for both ruptured and unruptured intracranial aneurysms [1-3]. Unfavorable anatomy as wide-neck aneurysms also require adjuvant therapy to be treated safety and efficiently [4, 5] knowing the fact that simple coiling or balloonassisted coiling has a high risk of coil protrusion in to the parent vessel. The use of stent-assisted coil embolization for wide-necked intracranial aneurysms has significantly expanded the range of aneurysms that are candidates for endovascular treatment [6-8]. However, single stent-assisted coiling in particular situations does not provide sufficient support when the neck of the aneurysm is centered on the bifurcation branches. In these cases, the use of two stents or Y-stenting has been proposed [9-12]. From technical point of view this technique remain challenging but it has high immediate and long-term occlusion rates [11].The waffle-cone technique is a feasible alternative to $Y$ stenting and consists of deploying the distal end of a dedicated stent, such as pCONus (Phenox $\mathrm{GmbH}$, Bochum, Germany) and PulseRider (Pulsar Vascular, San Jose, California, USA), inside the aneurysm sac and the proximal end in the parent artery. Coiling is performed through the expanded distal end of the stent. The main advantage of this technique is that both branches of the bifurcation are not involved in endovascular treatment. Small retrospective studies have evaluated and reported its safety and efficacy [13-15]. In asymmetric bifurcations where two or even three branches are arising from the neck level those techniques described above offer limited solutions and unpredictable branch protection during coiling. The use of flow diverters in wide-neck bifurcation aneurysms (WNBA) remains controversial owing to inconsistent patency of bifurcation branches covered by the stent and poor occlusion of the aneurysm at follow-up angiograms [16]. Targeted, large prospective multicenter studies are needed to evaluate the safety and efficacy of this treatment specifically for WNBA. Intrasaccular flow disruption devices, such as WEB (Woven EndoBridge; Microvention, Tustin, California, USA) are presently a feasible and efficient tool of WNBA treatment; moreover, retrospective and prospective studies confirmed the high safety level and low morbidity and mortality rates $[17,18]$. Despite the advantages of flow diversion in the case of complex irregular shapes and bi-lobed aneurysms or asymmetrical bifurcations, placing the WEB device proved to be unfeasible or at least very challenging even in experienced hands. In this context a single stent with "belly-like" central part which protects the adjacent branches in WNBA seems to be a promising solution for this type of aneurysms. Here, we report our single-center experience with Barrel VRD - stent assisted coiling, with clinical and angiographic periprocedural results, in order to evaluate the safety and efficiency of this technique.

\section{MATERIALS AND METHODS}

\section{Population}

We retrospectively reviewed interventional neuroradiology database records to identify patients in whom stenting with laser-cut or braided stents had been performed. We identified three patients treated with this technique in our institution between April 2015 and August 2018. Demographic data, aneurysm location and size are summarized in Table 1. All aneurysms were unruptured; all of them were primary endovascular treatments. In all cases, the aneurysm neck was wide, with an average dome to neck ratio of 1.49 .

\section{The Barrel vascular reconstruction device}

The Barrel device (Medtronic/Covidien, Irvine, California, USA) is a nitinol self-expandable, closedcell laser cut micro-stent with electrolytic detachment system. Two main characteristics offer two this type of stent the feasibility for WNBA's treatments. Main advantage is that due to "barrel" design that is represented by the "belly-like" central part of the stent protects the adjacent branches. Secondly due to the property to be re-sheathable up to three times.

\section{Endovascular technique}

Dual antiplatelet therapy was prescribed 2 days before the procedure as in all stent-assisted coiling treatment. In all patients, endovascular treatment was performed using a monoplane angiography unit with three-dimensional rotational capability (Allura Monoplan; Philips, Best, The Netherlands) under general anesthesia and systemic heparinization. 
After the procedure, dual antiplatelet therapy (Ticagrelor $2 \times 90 \mathrm{mg} /$ day and Aspirin $150 \mathrm{mg} /$ day) was administered for the first 3 months, and aspirin $160 \mathrm{mg} /$ day alone was administered for the following 9 months. In our department clopidogrel (Plavix $75 \mathrm{mg}$ ) was replaced by ticagrelor (Brilique 90 $\mathrm{mg}$ ) due to multiples advantages of the last one and also knowing that $20-25 \%$ of the subjects are naturally resistant to clopidogrel. A baseline activated clotting time (ACT) was obtained prior to the bolus infusion of heparin (30 to $50 \mathrm{lU} / \mathrm{kg}$ body weight), and hourly thereafter. The bolus infusion of heparin was followed by a continuous drip (1000 to $1500 \mathrm{IU} / \mathrm{h}$ ), with the purpose of doubling the baseline ACT. From the femoral arterial access, a $6 \mathrm{Fr} 100 \mathrm{~cm}$ distal-access catheter (Envoy/Codman, USA) was placed into the internal carotid artery or in the dominant vertebral artery. In all procedures, the most challenging branch of the bifurcation was first catheterized in order to place the distal tip of the stent. Then the simple deploying by retrieving the 0.021-inch microcatheter (Rebar 18, Medtronic, Irvine, $C A$, USA) was performed similar to Solitaire AB stent. The convenient placement of the "belly-like" central part of the stent was analyzed during the deployment in subtracted and non-subtracted angiograms. In all procedures the Barrel stent used was BV 4065 ("belly" diameter was 6,5mm and $4 \mathrm{~mm}$ proximal end diameter and $3.5 \mathrm{~mm}$ distal diameter) and in case 1 and 3 the satisfactory positioning of the stent was achieved after a first deployment. The precise placement of the "belly-like" central part of the stent is relatively simple to archive by the first attempt ( 2 out of our 3 cases). In one case the good positioning was achieved after third attempt due to acute angle between left PCA basilar trunk and consecutive drop of the microcatheter whine deploying the device. Each time the Barrel stent was safely re-sheeted inside Rebar 18 microcatheter and a new catheterization of the left PCA was done. In all three cases the aneurismal sac was microcatheterized easily through Barrel interstices after stent placement and detachment (no jailing technique was used). In all procedures, passing through both stents studs with 0.014-inch microguidewire was achieved without any technical incident. Finally, the aneurysm was coiled using detachable coils. After coiling in all three cases no collapse of the stent has been noticed neither thromboembolic event was noticed in the protected neck-sided branch.

\section{Complications}

No intra-procedural or delayed thromboembolic or hemorrhagic complication were noticed for all three cases treated in our department.

\section{Follow-up protocol}

At the end of the procedure, immediate control angiograms were obtained from all patients. Modified Raymond-Roy occlusion classification (RROC) was used for grading the occlusion status of coiled aneurysms. Patients underwent Angio-MRI at 3 months to reassess filling status of the coiled aneurysm, in-stent stenosis, and thrombosis. The modified Rankin scale was used for scoring neurologic status at discharge and follow-up.

\section{RESULTS}

All three treated aneurysms were un-ruptured. Procedural details and follow-up angiographic results are shown in Table 1. Treatment was successfully performed in all three cases. Angiographic results were categorized according to the revised RROC into one of the following groups: complete occlusion (RR1), remnant neck (RR2), or residual aneurysm (RR3) by two senior neuroradiologysts in consensus. There was no evidence of in-stent stenosis or thrombosis during follow-up Angio-MRI.

\section{DISCUSSION}

Stent-assisted coiling represents a wide world accepted solution for the treatment of wide-neck cerebral aneurysms over treatment with conventional coiling targeting higher rates of complete occlusion and lower rates of recurrence at long-term follow-up. However, treatment of WNBA and fusiform aneurysms is requiring a higher level of interventional neuro-endovascular skills and frequently requires a second stent (that is, a Y-, $\mathrm{X}$ - or waffle-cone-stenting configuration [19-20]) or dedicated endovascular stents such as pCONus, PulseRider, and Barrel stent [21]. There are currently little clinical data on these last three devices available. 
Despite the potential benefit of single stent-assisted coiling, complex aneurysms can pose a significant challenge for achieving immediate and durable embolization. Specifically, for wide-necked aneurysms located at shallow angle arterial bifurcations, single stent-mediated coiling may provide insufficient support of the coil mass to prevent coil herniation through the aneurysm neck.

A special situation is represented by the aneurysms with branches incorporated in the aneurysm base; Kim et al. [22] published a study with 68 patients with 78 intracranial aneurysms treated with multiple endovascular techniques: single-catheter coiling, multi-catheter coiling, balloon-assisted coiling, stentassisted coiling, and combined techniques. 5.8\% morbidity have been reported in this study and no mortality. 10 out of 55 (18\%) intracranial aneurysms had a recanalization from which six were retreated. It represents a significant proportion and, moreover, retreatments are even more challenging in this situation. In 2004, Chow et al detailed the Y-stent technique [12], whereby double open-cell Neuroform stents (Boston Scientific, Fremont, CA, USA) were deployed sequentially - first, proximal to the arterial bifurcation, and then into each arterial branch followed by coiling of the aneurysm sac. This represented an efficient endovascular solution for bifurcation lesions that are too complex for coiling alone, remodeling technique, or single-stent assisted coiling. Several authors have evaluated this technique in retrospective single-center studies, mostly including unruptured aneurysms [9-11]. The safety was relatively limited: Bartolini et al. reported $10.0 \%$ procedure-related permanent neurologic deficits and $1.0 \%$ death [10]. However, in other studies, the rate of intra-procedural complications was lower, with $4.2 \%$ in the study by Limbucci et al. and $2.7 \%$ in the study by Yavuz et al. with mortality rates of $2.1 \%$ and $0.5 \%$, respectively $[9,11]$. At longterm follow-up, the rate of complete aneurysm occlusion was high with $85.8 \%$ in the Bartolini study, 95.7\% in the Yavuz study, and $93.6 \%$ in the Limbucci study. Several types of stents can be used for $\mathrm{Y}$ stenting; mainly open-cell stents (Neuroform, Stryker Neurovascular, Fremont, California, USA) or closedcell stents (Enterprise, Codman, Miami Lakes, Florida, USA) have been reported. Intrasaccular flow disruption devices, such as the WEB device, are specially designed for the treatment of WNBA and have shown a high level of safety, with morbidity and mortality at 1-month post-procedure of $2.7 \%$ and $0.0 \%$, respectively [23]. The efficacy of this technique also proved to be higher than single-stent assisted coiling, and adequate occlusion was reported in $82.0 \%$ of cases at 12 months follow-up (complete occlusion: $56.0 \%$ and neck remnant: $26.0 \%$ ). Despite progressive technological improvements, such as the replacement of dual layer by single layer versions, and progressive decreases in the diameter of the micro-catheter used to deliver the device, there are still bifurcation aneurysms with challenging anatomy which are not suitable for this technique. More recently new WEB-balloon remodeling techniques have been described by Mihalea et al [24] where the WEB device can be deployed and tilted in the aneurysm sac using so called "balloon remodeling technique" and it may represent a feasible solution for this type of wide neck bifurcation aneurysms. In this category of wide neck aneurysms with branches incorporated at the neck level are technically particular and we strongly believe that Barrel stents represents a feasible and efficient solution. Moreover, it offers a solution for those anatomies where $\mathrm{Y}$-stenting is not a suitable solution as in recurrent branch anatomies like in the cases presented in this report (FIGURE 1, 2 and 3). Being a nitinol self-expandable, closed-cell laser cut microstent Barrel device is definitely less thrombogenic then braided stents that can be used for Y-stenting configuration. In our experience $Y$ stenting demands higher technical skills and prolonged duration of treatment and from this point of view the solution to protect the both side branches of an WBNA with only one stent is more elegant and particularly less susceptible to peroperative thromboembolic complications. Several particular anatomical conditions are feasible for this technique: a dome to neck ratio below 1,5; branches incorporated at the neck level usually with a smaller diameter (not suitable for stent deployment); polylobed bifurcation aneurysms; and asymmetry between the aneurysm plan and the bifurcation plan.

From a technical point of view, one of the main advantages over Y-stenting is represented by the fact that the stent micro-catheter $(0.021$-inch internal diameter) Rebar 18 in our cases, has to be placed only once at the level of desired branch and no recatheterization of the stent and second stent placement is needed. 
Pre Op

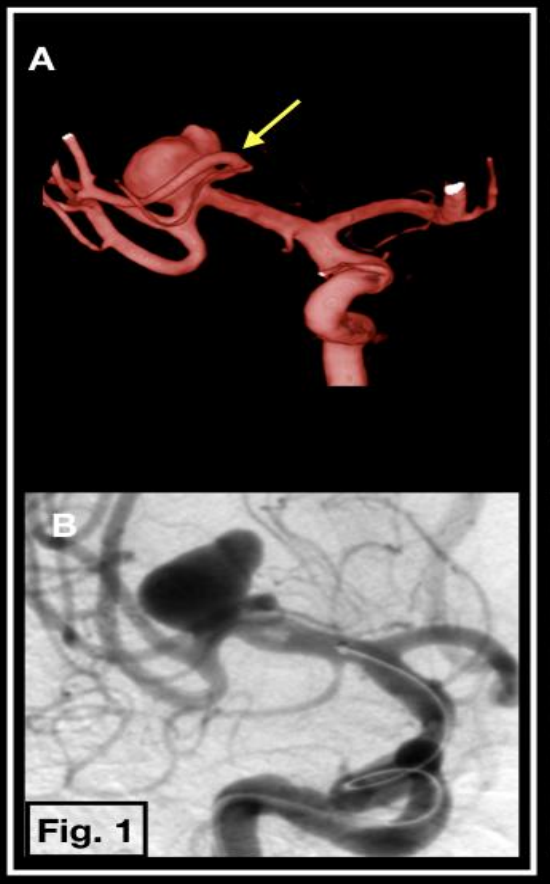

Intra Op

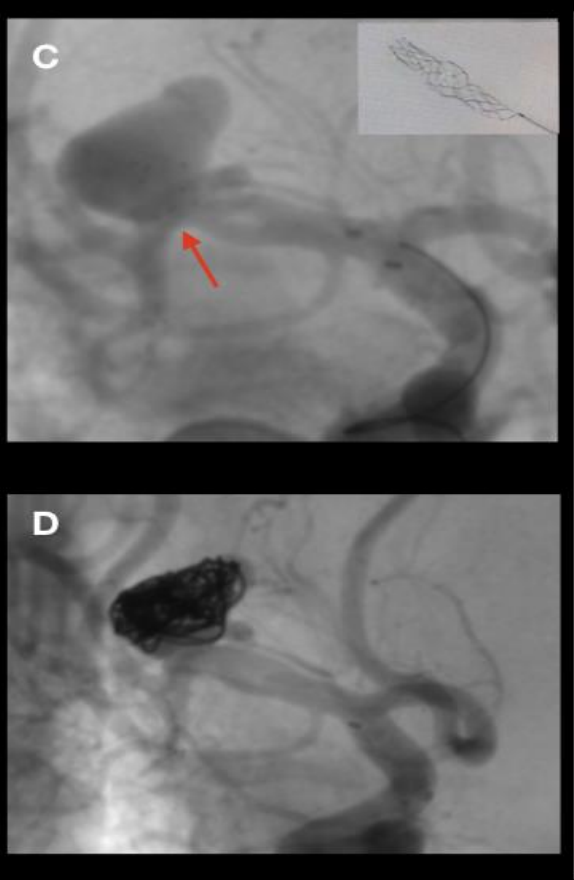

\section{Post Op}

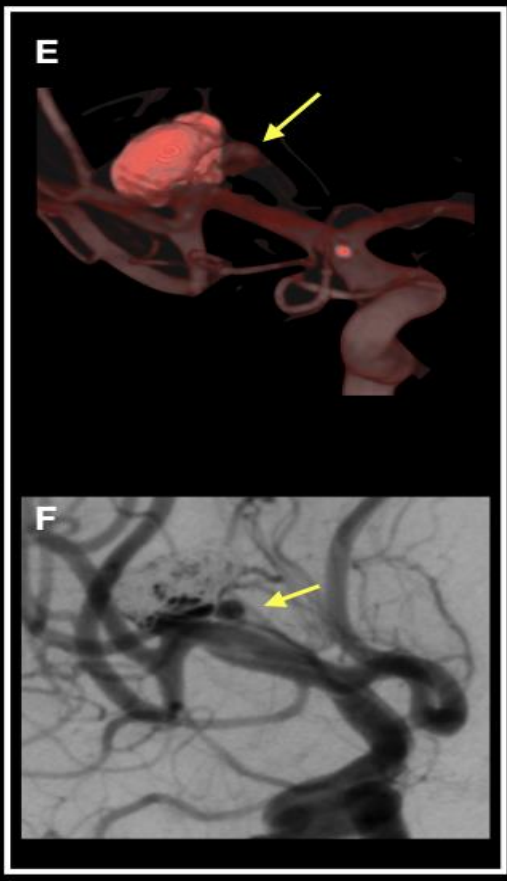

FIGURE 1. Right MCA bifurcation non-ruptured aneurysm with superior division of MCA arising from the neck level (yellow arrow). Barrel VRD was deployed in the inferior branch of the inferior division, the red arrow on Intra OP middle row (upper) indicates the radio-opaque markers protruding below the aneurysm neck. Post-Op pictures are demonstrating total occlusion of the aneurism sac and patency of the superior division of MCA.

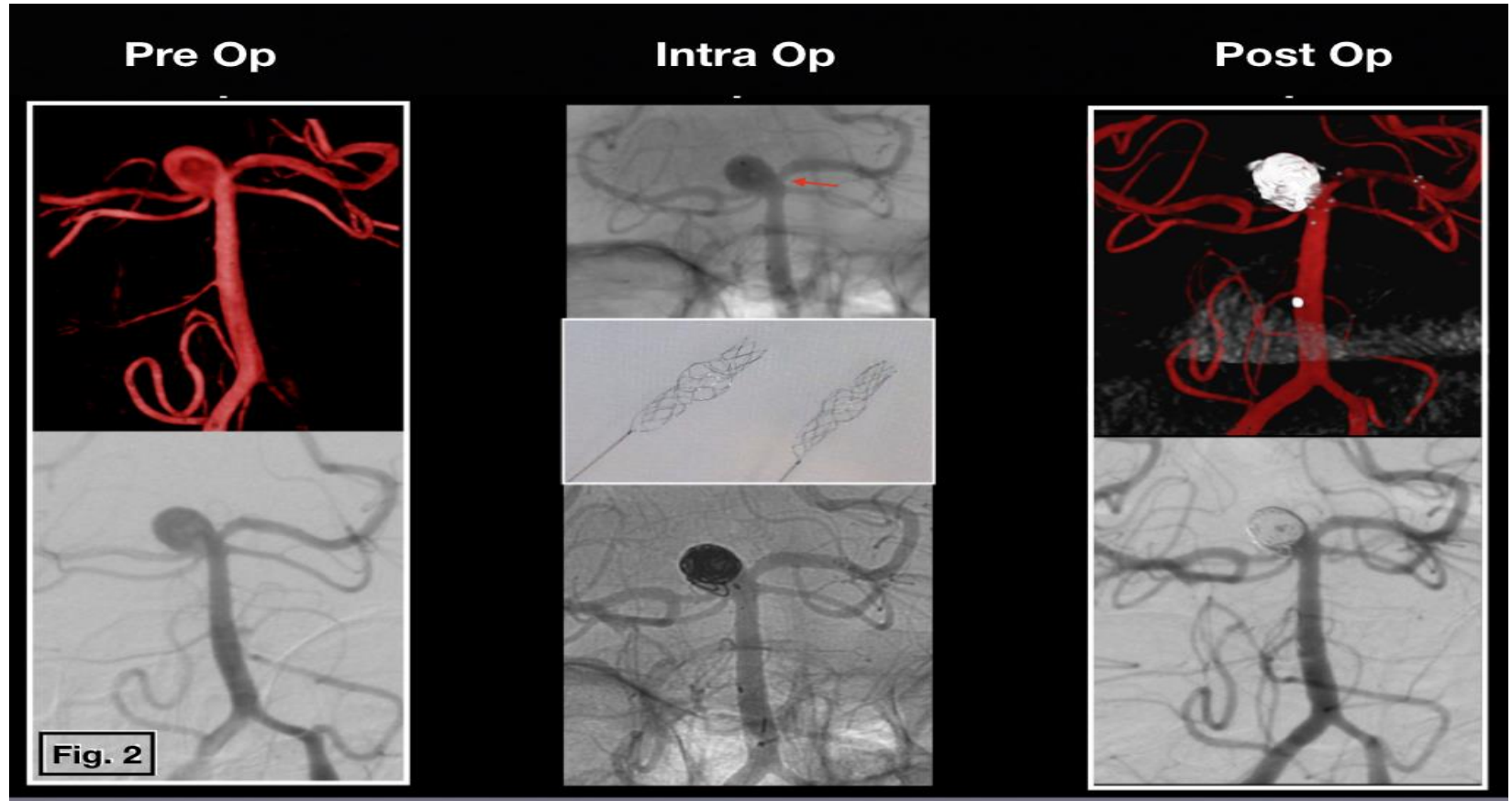

FIGURE 2. Basilar tip non-ruptured aneurysm with both PCA's arising from the neck level; Barrel VRD was deployed between the P1P2 segment of left PCA and the middle third of basilar artery. Post-Op pictures (3DRA and subtracted 2D images) are demonstrating total occlusion of the aneurism sac and patency of the both PCA's and SCA's arteries. 


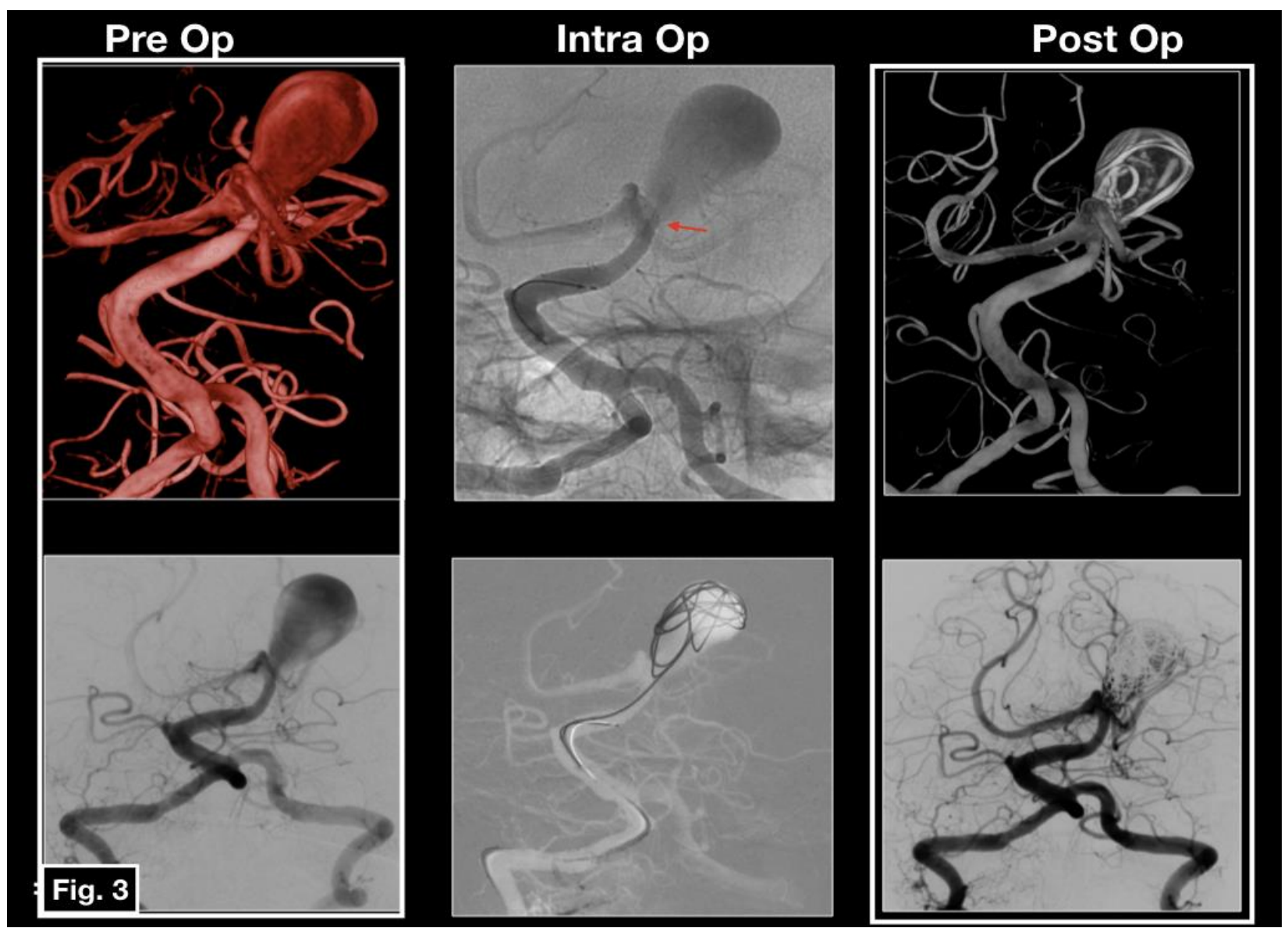

Fig 3. Giant basilar tip non-ruptured aneurysm with both PCA's arising from the neck level; Barrel VRD was deployed between the P1 segment of right PCA and the middle third of basilar artery. Red arrow indicating adequate apposition of the "belly" of the stent at the neck level with protection of both origins of PCA's. Post-Op pictures (3DRA and subtracted 2D images) are demonstrating adequate occlusion of the aneurism sac and patency of the both PCA's and SCA's arteries.

There is high visibility of the markers and positioning of the "barrel" at the neck level is clearly controlled under Road Map in conjunction with non-subtracted fluoroscopy (FIGURE 1 and 3; Intra-Op - middle row, upper image). In the same time the operator has to be aware that in angulated anatomies the stent positioning can be challenging and it requires reshiting of the stent. Is always preferable the more distal start of deploying than more proximal one. In this way we adjusted permanently the "barrel" part till the best matching with the neck is achieved. In all cases the stent has been detached once the deployment was proper and in the second time micro-catheterism through the stent struts was done without any technical difficulties with an 0,017 coiling microcatheter (Echelon 10/Medtronic,USA) . Coiling of the aneurysm sac was achieved using coils that were $1 \mathrm{~mm}$ smaller than aneurysm maximal diameter. This strategy allowed safe coiling of the sac and also avoided the micro-catheter expulsion from the aneurysm. In the current study, the initial immediate angiographic result was complete occlusion in all cases, and no recanalization occurred during follow-up. We found that this type of technique is useful in cases of asymmetrical WNBA, in which a WEB device is not a feasible solution and is less challenging than Y-stenting technique. In the same time, we are aware of the strong limitation of our small number of aneurysms treated by this technique and certainly further prospective studies comparing this technique with Y-stenting or WEB technique is needed in order to quantify the potential complication rates, long term angiographic outcomes.

\section{CONCLUSION}

WNBA remains challenging to endovascular treatment, although new devices that are dedicated 
to this type of anatomy are available. Barrel stent seems to be a promising device and difficult anatomies where Y-stenting or WEB device were only technical solution are now suitable for this technique. Main advantage of the device is the possibility to protect complex bifurcations or even trifurcations and branches incorporated at the neck level. However, further study using this technique in a prospective study with a large population and a long follow-up period is warranted.

\section{FUNDING STATEMENT}

This research received no specific grant from any funding agency in the public, commercial or not-for-profit sectors.

\section{COMPETING INTERESTS STATEMENT}

No Competing Interests to declare.

\section{REFERENCES}

1. Molyneux A, Kerr R, Stratton I, et al. International Subarachnoid Aneurysm Trial (ISAT) of neurosurgical clipping versusendovascular coiling in 2143 patients with ruptured intracranialaneurysms: a randomised trial. Lancet 2002;360:1267-74.

2. Cognard C, Pierot L, Anxionnat R, Ricolfi F, Clarity Studygroup. Results of embolization used as the first treatmentchoice in a consecutive nonselected population of rupturedaneurysms: clinical results of the Clarity GDC study. Neuro-surgery 2011;69:837-41.

3. Pierot $L$, Spelle L, Vitry $F$, for the ATENA investigators. Clinical outcome of patients harbouring unruptured intracranialaneurysms treated by endovascular approach: results of theATENA trial. Stroke 2008;39:2497-504.

4. Pierot L, Cognard C, Spelle L, Moret J. Safety and efficacy ofballoon remodeling technique during endovascular treatmentof intracranial aneurysms: critical review of the literature.AJNR Am J Neuroradiol 2012;33:12-5.

5. Pierot L, Spelle L, Leclerc X, Cognard C, Bonafé A, Moret J.Endovascular treatment of unruptured intracranial aneurysms:comparison of safety of remodeling technique and standardtreatment with coils. Radiology 2009;251:846-55.

6. Gentric JC, Biondi A, Piotin M, et al. Balloon remodeling mayimprove angiographic results of stent-assisted coiling of unrup-tured intracranial aneurysms. Neurosurgery 2015;76:441-5.

7. Piotin $M, B$ Blanc $R$, Spelle $L$, et al. Stent-assisted coiling of intracranial aneurysms: clinical and angiographic results in 216consecutive aneurysms. Stroke 2010;41:110-5.

8. Hetts SW, Turk A, English JD, et al. Stent-assisted coiling versus coiling in unruptured intracranial aneurysms in the
Matrixand Platinum Science trial: safety, efficacy, and midterm out-comes. AJNR Am J Neuroradiol 2014;35:698-705.

9. Yavuz K, Geyik S, Cekirge S, Saatchi I. Double stent-assisted coilembolization treatment for bifurcation aneurysms: immediatetreatment results and long-term angiographic outcome. AJNRAm J Neuroradiol 2013;34:1778-84.

10. Bartolini B, Blanc R, Pistocchi S, Redjem H, Piotin M. « $Y$ » and « $X$ » stent-assisted coiling of complex and wideneckintracranial bifurcation aneurysms. AJNR Am J Neuroradiol 2014;35:2153-8.

11. Limbucci N, Renieri L, Nappini S, et al. Y-stent assisted coiling of bifurcation aneurysms with Enterprise stent: longtermfollow-up. J Neurointerv Surg 2016;8:158-62,

12. Chow MM, Woo HH, Masaryk TJ, et al. A novel endovascular treatment of a wide-necked basilar apex aneurysm by using a Y-configuration, double-stenttechnique. AJNR Am J Neuroradiol 2004;25:509-12.

13. Aguilar-Pérez $M$, Kurre W, Fischer S, Bäzner $H$, Henkes $H$. Coil occlusion of wide-neck bifurcation aneurysms assistedby a novel intra- to extra-aneurysmatic neckbridgingdevice (pCONus): Initial experience. AJNR Am J Neuroradiol2014;35:965-71.

14. Gory B, Aguilar-Pérez M, Pomero E, et al. pCONus devicefor the endovascular treatment of wide-neck middle cerebralartery aneurysms. AJNR Am J Neuroradiol 2015;36:1735-40,http://dx.doi.org/10.3174/ajnr.A4392.

15. Spiotta AM, Chaudry MI, Turk AS, Turner RD. Initial experience with the PulseRider for the treatment of bifurcationaneurysms: report of first three cases in the USA. JNeurointerv Surg 2016;8:186-9, http://dx.doi.org/10.1136/neurintsurg-2014-011531.

16. Gawlitza M, Januel AC, Tall P, Bonneville F, Cognard C.Flow diversion treatment of complex bifurcation aneurysmsbeyond the circle of Willis: a single center series with spe-cial emphasis on covered cortical branches and perforatingarteries. J Neuro Intervent Surg 2015, http://dx.doi.org/10.1136/neurintsurg-2015-011682.

17. Pierot L, Moret J, Turjman F, et al. WEB treatment of intracra-nial aneurysms: clinical and anatomical results in the FrenchObservatory. AJNR Am J Neuroradiol [Epub ahead of print].

18. Pierot L, Spelle L, Molyneux A, Byrne J, WEBCAST and FrenchObservatory investigators. Clinical and anatomical follow-up inpatients with aneurysms treated with the WEB device: 1-yearfollow-up report in the cumulated population of 2 prospec-tive, multicenter series (WEBCAST and French Observatory). Neurosurgery 2016;78:133-41

19. Bartolini B, Blanc R, Pistocchi $S$, et al. " $Y$ " and " $X$ " stentassisted coiling of complex and wide-neck intracranial bifurcation aneurysms. AJNR Am J Neuroradiol2014;35:2153-8.

20. Saatci I, Geyik S, Yavuz K, et al. X-configured stent-assisted coiling in the endovascular treatment of complex anterior 
communicating artery aneurysms: a novel reconstructive technique. AJNR Am J Neuroradiol 2011;32:E113-17.

21. Piotin M, Blanc R, Berge J, et al. The Barrel VRDTM vascular reconstruction device for the treatment of wide-neck bifurcation aneurysms. Stroke 2015;46(Suppl 1): AWP86.

22. Kim BM, Park SI, Kim DJ et al (2010) Endovascular coil embolization of aneurysms with a branch incorporated into the sac. AJNR Am J Neuroradiol 31:145-151

23. Pierot L, Spelle L, Molyneux A, Byrne J, WEBCAST and FrenchObservatory investigators. Clinical and anatomical follow-up inpatients with aneurysms treated with the WEB device: 1-yearfollow-up report in the cumulated population of 2 prospective, multicenter series (WEBCAST and French Observatory). Neurosurgery 2016;78:133-41.

24. Cristian Mihalea, Simon Escalard, Jildaz Caroff, Léon Ikka, Aymeric Rouchaud, Valerio Da Ros, Igor Pagiola, Joaquin Jose Marenco de la Torre1, Thomas Yasuda1, Bogdan Valeriu Popa, Horia Ples, Nidhal Benachour, Augustin Ozanne, Jacques Moret1, Laurent Spelle; Balloon remodeling-assisted Woven EndoBridge technique: description and feasibility for complex bifurcation aneurysms; J Neurointerv Surg. 2018 Oct 5. pii: neurintsurg2018-014104. doi: 10.1136/neurintsurg-2018-014104. 